\title{
Identificación de variantes genéticas asociadas a la sensibilidad solar
}

\author{
Julio Alberto Deserio-Cuesta \\ al224979@uji.es \\ RAQUEL SORIA-NAVARRO \\ al224942@uji.es \\ INCA VILAR-SASTRE \\ al224960@uji.es \\ BÁRBARA HERNANDO \\ hernandb@uji.es \\ ConRado Martínez-CADENAS \\ ccadenas@uji.es
}

\section{Resumen}

Introducción: La sensibilidad a la radiación ultravioleta está determinada por características pigmentarias influenciadas por varios genes. Ciertos rasgos de la pigmentación, como tener un color de piel claro, tener muchas efélides y/o nevus y una dificultad de bronceado, son indicadores de una mayor susceptibilidad a esta radiación solar $y$, por tanto, al cáncer de piel. Sin embargo, poco se conoce sobre los determinantes genéticos asociados a la sensibilidad solar, a excepción del gen MC1R. Este estudio analiza las bases genéticas de la sensibilidad solar y la predisposición al cáncer cutáneo en una población española. Metodología: En el estudio participaron 300 voluntarios. Mediante un cuestionario estandarizado, se recogieron características fenotípicas de pigmentación, historia de quemaduras solares y hábitos de exposición solar. Para cada individuo, se determinó el genotipo de genes involucrados en la ruta de la pigmentación humana - MC1R, ASIP, TYR, OCA2, HERC2, SLC24A4, BNC2, IRF4, $K I T L G$, y SLC45A2. El análisis de asociación entre las características fenotípicas y el genotipo se realizó con una regresión logística, utilizando el programa SPSS v24. Resultados: El mayor determinante genético de los rasgos de pigmentación y sensibilidad solar es el gen MC1R. Polimorfismos en IRF4, ASP y SLC45A2 también parecen influir en la pigmentación cutánea basal, así como en la aparición de lesiones hiperpigmentadas benignas. Conclusión: Los individuos con fenotipo de riesgo tienen significativamente mayor número de polimorfismos asociados con una peor tolerancia al sol. Individuos portadores de estos polimorfismos tendrían una mayor sensibilidad a la radiación solar y, por tanto, a padecer cáncer cutáneo.

Palabras clave: Pigmentación humana, Sensibilidad solar, Lesiones hiperpigmentarias benignas, Polimorfismos, $M C 1 R$ 


\section{Abstract}

Introduction: Sensitivity to ultraviolet radiation is determined by pigmentation traits, which are influenced by several genes. Particular pigmentation characteristics, such as having fair skin, having ephelides and/or naevi, and the inability to tan, are associated with a high sensitivity to sunlight and, therefore, a predisposition to skin cancer. However, little is known about the genetic determinants associated with sunlight sensitivity, apart from MC1R gene. This study analyses the genetic basisof sunlight sensitivity and skin cancer susceptibility in a Spanish population. Methodology: Three-hundred volunteers participated in the study. Phenotypic characteristics of pigmentation, history of sunburn and sun exposure behaviour were collectedby using a standardized questionnaire. For each participant, we examined the genotype of the following genes involved in the human pigmentation pathway: MC1R, ASIP, TYR, OCA2, HERC2, SLC24A4, BNC2, IRF4, KITLG, and SLC45A2. To determine the association with phenotypic characteristics, a logistic regression was performed for each polymorfism. Statistical analysis were perfomed by using SPSS v24 software. Results: The major genetic determinant of pigmentation and sunlight sensitivity traits is the MC1R gene. Polymorphisms in IRF4, ASIP and SLC45A4 also seems to impacton basal skin pigmentation, as well as on the appearance of benign hyperpigmented lesions. Conclusion: Individuals having a risk phenotype carry significantly a higher number of genetic variants associated with reduced tolerance to sun exposure. Individuals carrying these polymorphisms would have a higher sensitivity to UV radiation and, therefore, an increased susceptibility todevelop skin cancer.

Keywords: Human pigmentation, Sunlight sensitivity, Benign hyperpigmented lesions, Polymorphisms, MC1R.

\section{Introducción}

Los rasgos de pigmentación humana, como el color de ojos, piel y pelo, son los rasgos fenotípicos más diferenciables entre humanos. La pigmentación humana está principalmente determinada por la cantidad y el tipo de melanina en la epidermis, iris y pelo (Praetorius, Sturm, y Steingrimsson, 2014; Ryung Roh, Eliades, Gupta, Grant-Kels, y Tsao, 2015). La melanina de la piel, producida como respuesta a la exposición a los rayos ultravioleta procedentes del sol, protege al ADN del núcleo de las células impidiendo que esta radiación produzca daño celular (Praetorius y cols., 2014; Scherer y Kumar, 2010). Existen dos tipos de melanina: la eumelanina, de color marrón-negruzca con elevada capacidad de absorber la radiación ultravioleta; y la feomelanina, de color rojizo-amarillento compuesta de unidades de benzotiazina que en gran medida es responsable del pelo rojo y las pecas (Scherer y Kumar, 2010).

La sensibilidad solar es el término referido a la capacidad de la piel de responder a la exposición solar. La aparición de quemaduras y la imposibilidad de bronceado son rasgos característicos de una mala respuesta al sol, siendo también indicadores de una mayor susceptibilidad a aparición de lesiones hiperpigmentadas benignas así como a desarrollar un cáncer cutáneo (Hernando, Ibarrola-Villava, Peña-Chilet, y cols., 2016; Scherer y Kumar, 2010; Sulem y cols., 2007). El grado de sensibilidad cutánea a la exposición solar está definido por rasgos de pigmentación determinados genéticamente, como tener el color de piel clara, 
los ojos azules o verdes, el pelo rubio o rojo, así como tener muchas pecas o lunares (Jacobs y cols., 2015).

Los rasgos de pigmentación son de carácter poligénico, es decir, están influenciados por muchísimos genes con efectos relativamente pequeños. Son muchos los estudios que han descrito variantes genéticas localizadas en genes relacionados con la pigmentación humana asociadas a fenotipos pigmentarios de riesgo y de sensibilidad solar, así como con el riesgo a cáncer de piel (Avilés y cols., 2012; Bastiaens y cols., 2001; Córdoba-Lanús y cols., 2014; Fernandez y cols., 2007; Law, MacGregor, y Hayward, 2012; Matichard y cols., 2004). Uno de los genes más estudiados, debido a su clara y directa asociación con fenotipos de sensibilidad solar, es el receptor de melanocortina $1(M C 1 R)$. La secuenciación de este gen ha permitido identificar la existencia de más de 100 variantes alélicas no sinónimas en poblaciones Caucásicas. Seis variantes han sido relacionadas con el color rojo de pelo, piel clara y la aparición de efélides (variantes RHC, red haircolour): D84E, R142H, R151C, I155T, R160W y D294H (Fernandez y cols., 2007; Ibarrola-Villava y cols., 2014). Asimismo, se han descrito otros genes que también parecen estar involucrados en la pigmentación y en la capacidad de respuesta a la exposición solar, como BNC2, IRF4, TYR, ASP o SLC45A2 (Eriksson y cols., 2010; Jacobs y cols., 2015; Scherer y Kumar, 2010).

Sin embargo, poco se conoce de su implicación de estos genes en el riesgo de aparición de lesiones hiperpigmentarias benignas y la predisposición a los diferentes cánceres de piel en la población española. Por ello, este estudio intentará esclarecer cuáles son las variantes genéticas que determinan la sensibilidad solar cutánea en la población española.

\section{Métodos}

\section{Sujetos y recogida de datos}

Se incluyeron un total de 300 individuos de origen español (150 hombres y 150 mujeres). Este estudio se engloba dentro de un proyecto de investigación el cual ha sido aprobado por la Comisión Deontológica de la Universitat Jaume I de Castellón. Todos los participantes firmaron un consentimiento informado.

Se utilizó un cuestionario estandarizado para recoger datos de filiación (edad, sexo y lugar de nacimiento), hábitos de exposición solar y características de sensibilidad solar cutánea. Cada rasgo fenotípico de sensibilidad solar fue clasificado en dos categorías: fototipo cutáneo I-II o III-IV, presencia o ausencia de lentigos solares, número de nevus menor o mayor de 25, presencia o ausencia de efélides, y presencia o ausencia de quemaduras solares en la infancia.

EI DNA genómico de cada individuo se obtuvo de una muestra de saliva. La extracción del DNA se realizó utilizando QIAamp DNA Mini Kit (Qiagen), siguiendo las recomendaciones del fabricante.

\section{Genotipado de variantes genéticas}

Se analizó un total de 10 polimorfismos (SNPs) localizados en genes previamente asociados a rasgos de pigmentación humana y sensibilidad solar (HERC2, ASP, OCA2, TYR, SLC45A2, BNC2, IRF4, SLC24A4 y KITLG). Todas las reacciones de genotipado se realizaron utilizando KASP SNP Genotyping Chemistry (LGC, Hoddesdon, Reino Unido) y TaqMan SNP Genotyping Assays (Applied Biosystems, California, EEUU). El análisis de la genotipación se 
llevó a cabo utilizando el equipo de PCR a tiempo real StepOnePlusTM (AppliedBiosystems, Foster City, CA, EE.UU.), y utilizando el software SDS 2.1 para el análisis de discriminación alélica (AppliedBiosystems)

Como medida de control de calidad, se incluyeron tres controles positivos (un heterocigoto, un homocigoto del alelo ancestral y un homocigoto del alelo derivado) y un control negativo por placa de 96 pocillos.

\section{Secuenciación del gen $M C 1 R$}

El ensayo genotípico del gen MC1R se realizó mediante la secuenciación completa de la región codificante del gen, ya que se trata de un gen altamente polimórfico. Una vez amplificada la región codificante del gen, los productos de la PCR fueron purificados utilizando exonucleasa I y fosfatasa alcalina (Roche Molecular Bioquímicos AQ2, Mannheim, Alemania). El análisis de secuenciación se realizó utilizando la tecnología Sanger Sequencing. Los individuos fueron clasificados según eran portadores o no de variantes RHC del gen.

\section{Análisis estadístico}

Inicialmente, se realizó un test Chi-cuadrado tanto para comprobar el cumplimiento del equilibrio de Hardy-Weinberg (HWE) como para comparar la distribución de la frecuencia del alelo menor (MAF) de la población española y las poblaciones europeas de referencia: Utah residents with Northern and Western European ancestry(CEU) y Toscani in Italy (TSI). Los datos de estas poblaciones fueron extraídos de la base de datos ensembl (http://www.ensembl.org/).

Posteriormente, para determinar si existe una asociación entre las diferentes características fenotípicas y las variables genéticas estudiadas se llevó a cabo una regresión logística binaria (considerando el modelo genético de herencia aditivo). Para cada asociación se obtuvo el valor $p$ bilateral ( $P$-value), el odd ratio $(\mathrm{OR})$ y el correspondiente intervalo de confianza (IC).

Todos los análisis estadísticos se realizaron mediante el programa estadístico informático SPSS v24 y el Excel 2013.

\section{Resultados}

Antes de realizar los análisis genéticos, se llevó a cabo un análisis descriptivo para observar la distribución de las características de sensibilidad solar en nuestra población (número de nevus, historia de quemaduras solares, lentigos solares, fototipo cutáneo y efélides), formada por 150 hombres y 150 mujeres de origen español (Figura 1). 


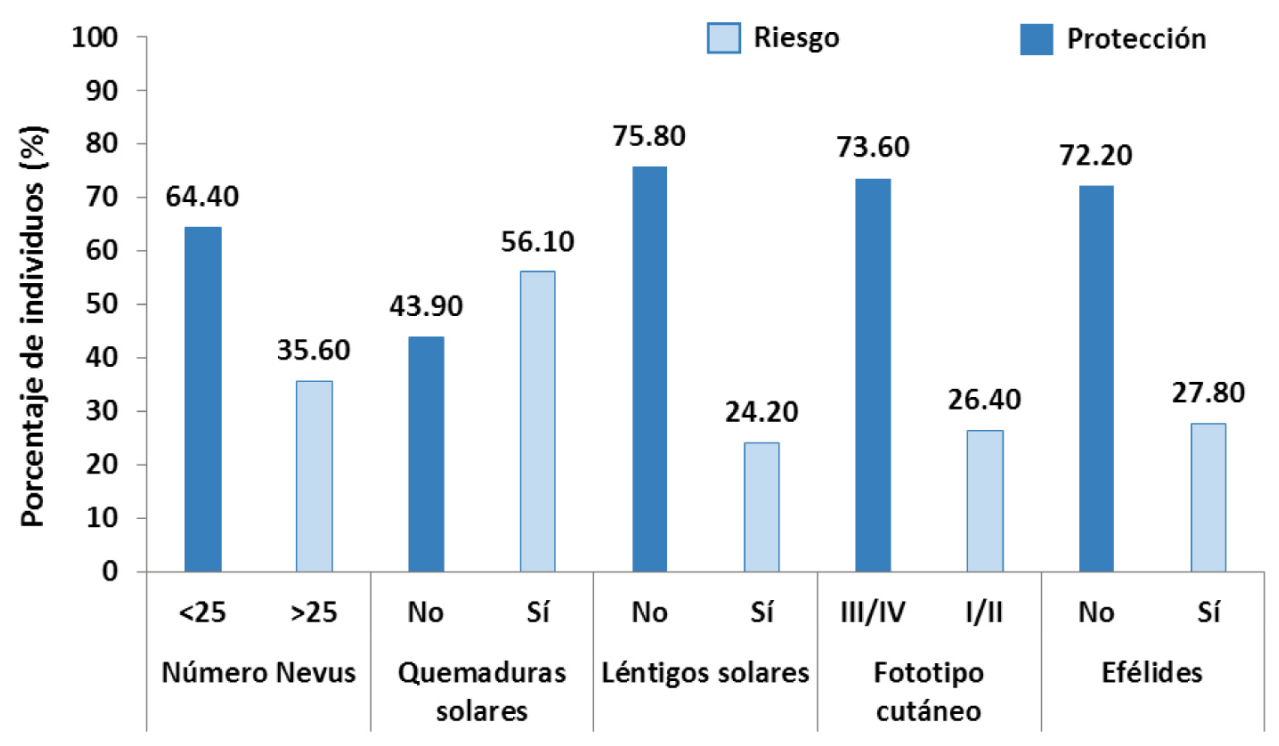

Figura 1.Distribución de características pigmentarias de sensibilidad solar en el total de individuos de la población española. Las barras representan el porcentaje de individuos del total que presenta cada característica según indica la leyenda

Tabla 1

Distribución de la frecuencia alélica en las diferentes poblaciones europeas

\begin{tabular}{|c|c|c|c|c|c|c|c|c|}
\hline \multirow{2}{*}{ Gen } & \multirow{2}{*}{ SNP } & \multirow{2}{*}{ Alelo Menor ${ }^{a}$} & \multirow{2}{*}{ MAF CEU } & \multirow{2}{*}{ MAF TSI } & \multicolumn{2}{|c|}{ Población España } & \multirow{2}{*}{$P$-value $\mathrm{CEU}^{\mathrm{e}}$} & \multirow{2}{*}{$P$-value $\mathrm{TSI}^{\mathrm{e}}$} \\
\hline & & & & & MAF España & $\mathrm{pHWE}^{\mathrm{d}}$ & & \\
\hline OCA2 & rs1800407 & $\mathrm{T}$ & 0,081 & 0,098 & 0,078 & 0,402 & 0,896 & 0,390 \\
\hline HERC2 & rs12913832 & $T^{b}$ & 0,232 & 0,579 & 0,576 & 0,477 & $1,00 \mathrm{E}-05$ & 0,926 \\
\hline$A S P$ & rs4911442 & $\mathrm{G}$ & 0,121 & 0,056 & 0,081 & 0.107 & 0,087 & 0,237 \\
\hline$B N C 2$ & rs2153271 & C & 0.399 & 0,435 & 0,457 & 0,054 & 0,153 & 0,569 \\
\hline IRF4 & rs12203592 & $A$ & 0,162 & 0,093 & 0,140 & 0,866 & 0,449 & 0,083 \\
\hline TYR1 & rs1393350 & A & 0,242 & 0,248 & 0,230 & 0,486 & 0,715 & 0,597 \\
\hline TYR2 & rs1042602 & $A$ & 0,399 & 0,486 & 0,460 & 0,638 & 0,140 & 0,173 \\
\hline$S L C 24 A 4$ & rs12896399 & $G^{c}$ & 0,439 & 0,617 & 0,437 & $4,00 \mathrm{E}-03$ & 0,946 & $1,00 \mathrm{E}-05$ \\
\hline SLC45A2 & rs16891982 & C & 0,020 & 0,033 & 0,113 & 0,161 & $1,00 \mathrm{E}-04$ & $5,00 \mathrm{E}-04$ \\
\hline KITLG & rs12821256 & C & 0,131 & 0,037 & 0,041 & 0,483 & $1,00 \mathrm{E}-05$ & 0,817 \\
\hline
\end{tabular}

Los valores resaltados en negrita son estadísticamente significativos $(P$-value $<0,05)$.

${ }^{\text {a }}$ Alelo menor de la población caucásica de referencia CEU

${ }^{\mathrm{b}}$ Alelo con mayor frecuencia en la población italiana y española, que representa el mayoritario en estas poblaciones sur-europeas

${ }^{c}$ Alelo con mayor frecuencia en la población italiana, que representa el alelo mayoritario en la población TSI

${ }^{d}$ pHWE es el $P$-value obtenido al analizar el cumplimiento del equilibrio de Hardy-Weinberg mediante un test Chi-cuadrado

${ }^{\mathrm{e}} P$-value obtenido al compara las MAF de la población española con las MAF de CEU y TSI mediante un test Chi-cuadrado

Todos los SNPs estudiados cumplieron el equilibrio de Hardy-Weinberg, a excepción de SLC24A4 rs12896399 que fue descartado en los análisis de asociación posteriores (Tabla 1). La distribución alélica de HERC2 rs12913832, SLC45A2 rs16891982 y KITLG rs12821256 en la población española es significativamente diferente a la distribución observada en la población de referencia del norte de Europa (CEU). Asimismo, SLC24A4 rs12896399 y SLC45A2 
rs16891982 presentan una frecuencia del alelo menor diferente en nuestra población de origen español respecto a la descrita en la población de referencia del sur de Europa (TSI) (Tabla 1).

Posteriormente, se realizó un análisis para determinar si existe una asociación entre el genotipo y las características fenotípicas de sensibilidad solar. Para llevar a cabo este análisis de asociación se utilizó una regresión logística binaria entre cada variante genética y cada uno de los rasgos fenotípicos incluidos en el estudio (Tabla 2). Tres polimorfismos presentan una asociación significativa con la presencia de efélides (OR>1): rs12203592*A del gen IRF4 ( $P$ value $=0.026)$, rs $4911442^{*} \mathrm{G}$ del gen $A S P(P$-value $=0.048)$ y las variantes $\mathrm{RHC}$ del gen $M C 1 R$ $\left(P\right.$-value $\left.=5.00 \times 10^{-6}\right)$. Únicamente IRF4 rs12203592 está significativamente correlacionado con la presencia de léntigos solares $(O R>1, P$-value $=0.029)$. Nuestros resultados revelan que las variantes $\mathrm{RHC}$ del gen MC1R predisponen a tener un fototipo cutáneo bajo $(P$-value $=$ $\left.1.00 \times 10^{-3}\right)$, y por consiguiente incrementan el riesgo a quemaduras solares cutáneas tras la exposición solar $(P$-value $=0.026)$. Sin embargo, el alelo C de SLC45A2 rs16891982 predispone a tener un fototipo alto $(\mathrm{OR}<1, P$-value $=0.016)$.

Tabla 2

Asociación del genotipo con cada una de las características pigmentarias de sensibilidad solar

\begin{tabular}{|c|c|c|c|c|c|c|c|c|}
\hline \multirow{2}{*}{ Gen } & \multirow{2}{*}{ SNP } & \multirow{2}{*}{ Alelo- } & \multicolumn{2}{|r|}{ Efélides } & \multicolumn{2}{|c|}{ Lentigos solares } & \multicolumn{2}{|c|}{ Quemaduras solares } \\
\hline & & & P-value & OR $(95 \%$ IC) & P-value & OR (95\% IC) & P-value & OR $(95 \%$ IC) \\
\hline TYR & rs1042602 & A & 0,747 & $0,94(0,65-1,36)$ & 0,35 & $0,83(0,56-1,23)$ & 0,055 & $0,71(0,50-1,01)$ \\
\hline$T Y R$ & rs 1393350 & A & 0,263 & $1,28(0,83-1,95)$ & 0,783 & $0,94(0,59-1,48)$ & 0,744 & $0,94(0,63-1,34)$ \\
\hline$S L C 45 A 2$ & rs16891982 & $\mathrm{C}$ & 0,66 & $0,88(0,50-1,56)$ & 0,12 & $0,58(0,29-1,15)$ & 0,869 & $0,96(0,58-1,59)$ \\
\hline IRF4 & rs12203592 & A & 0,026 & $1,76(1,07-2,89)$ & 0,029 & $1,77(1,06-2,96)$ & 0,829 & $1,05(0,66-1,70)$ \\
\hline$A S P$ & rs4911442 & G & 0,048 & $1,80(1,01-3,24)$ & 0,155 & $1,55(0,85-2,84)$ & 0,309 & $1,36(0,75-2,47)$ \\
\hline HERC2 & rs12913832 & $\mathrm{T}$ & 0,118 & $0,69(0,43-1,10)$ & 0,127 & $0,72(0,47-1,10)$ & 0,178 & $0,76(0,51-1,14)$ \\
\hline OCA2 & rs 1800407 & $\mathrm{~T}$ & 0,685 & $1,19(0,52-2,70)$ & 0,519 & $1,28(0,60-2,73)$ & 0,789 & $0,91(0.44-1,87)$ \\
\hline KITLG & rs12821256 & C & 0,494 & $0,70(0,25-1,96)$ & 0,343 & $0,55(0,16-1,91)$ & 0,576 & $0,78(0,33-1,87)$ \\
\hline MC1R & RHC variants & $\mathrm{RHC}$ & $5,00 \mathrm{E}-06$ & $3,79(2,14-6,71)$ & 0,92 & $0,97(0,53-1,77)$ & 0,026 & $1,94(1,08-3,47)$ \\
\hline \multirow{2}{*}{ Gen } & \multirow{2}{*}{ SNP } & \multirow{2}{*}{ Alelo- } & \multicolumn{2}{|c|}{ Fototipo cutáneo } & \multicolumn{2}{|c|}{ Número de nevus } & & \\
\hline & & & P-value & OR (95\% IC) & P-value & OR (95\% IC) & & \\
\hline TYR & rs 1042602 & A & 0,976 & $1,01(0,69-1,47)$ & 0,084 & $0,73(0,51-1,04)$ & & \\
\hline TYR & rs 1393350 & A & 0,917 & $1,02(0,66-1,59)$ & 0,147 & $1,34(0,90-1,99)$ & & \\
\hline SLC45A2 & rs16891982 & C & 0,016 & $0,34(0,19-0,84)$ & 0,438 & $0,81(0,47-1,39)$ & & \\
\hline IRF4 & rs12203592 & A & 0,419 & $1,24(0,74-2,07)$ & 0,829 & $0,95(0,58-1,55)$ & & \\
\hline$A S P$ & rs4911442 & $G$ & 0,512 & $1,23(0,67-2,26)$ & 0,955 & $0,98(0,55-1,77)$ & & \\
\hline HERC2 & rs12913832 & $\mathrm{T}$ & 0,346 & $0,79(0,48-1,29)$ & 0,57 & $0,89(0,59-1,34)$ & & \\
\hline OCA2 & rs1800407 & $\mathrm{T}$ & 0,977 & $1,01(0,41-2,51)$ & 0,242 & $0,61(0,27-1,39)$ & & \\
\hline KITLG & rs12821256 & C & 0.621 & $0,77(2,73-2,17)$ & 0,447 & $0,69(0.26-1,82)$ & & \\
\hline$M C 1 R$ & $\mathrm{RHC}$ variants & $\mathrm{RHC}$ & $1.00 \mathrm{E}-03$ & $2,53(1,46-4,41)$ & 0,508 & $1,20(0,70-2,04)$ & & \\
\hline
\end{tabular}

Los valores resaltados en negrita son estadísticamente significativos $(P$-value $<0.05)$

\section{Discusión y conclusiones}

En este estudio, se ha recogido información de varias características pigmentarias de sensibilidad solar cutánea (fototipo cutáneo, lentigos solares, número de nevus, efelides, e historia de quemaduras solares) y determinado el genotipo de diferentes genes relacionados 
con la pigmentación humana de 300 individuos de origen español. El objetivo del era analizar si existen variantes genéticas específicas que incrementen la sensibilidad solar cutánea.

Inicialmente se realizó una descripción de nuestra población de acuerdo a las variables fenotípicas incluidas en el análisis. La distribución de las características fenotípicas en nuestra población española son concordantes con otros estudios realizados en poblaciones mediterráneas (Candille y cols., 2012; Ibarrola-Villava y cols., 2011; Martinez-Cadenas, Peña-Chilet, Ibarrola-Villava, y Ribas, 2013), donde los individuos suelen presentar fototipos cutáneos altos (III/IV) y la prevalencia de efélides es baja (Figura 1). Destacar el bajo número de individuos que presentan lentigos solares $(24.20 \%)$, seguramente debido a que la mayoría de individuos incluidos en el estudio tiene menos de 35 años y los lentigos solares son lesiones hiperpigmentadas benignas relacionadas principalmente con el fotoenvejecimiento (Ezzedine y cols., 2013). Por otro lado, es interesante que, aunque la mayoría de individuos tengan una buena capacidad de respuesta a la exposición solar (fototipos III/IV), existe un elevado porcentaje de la población que ha sufrido quemaduras solares en la infancia (56.10\%). Una causa que podría explicar estos resultados es que los individuos incluidos en el estudio residen en la zona del Levante donde, debido a las buenas condiciones climáticas, la gente podría estar más expuesta a las radiaciones solares que en otras regiones de España.

A continuación, se realizó una comparación entre la distribución de la frecuencia alélica entre nuestra población y las dos poblaciones europeas de referencia (CEU y TSI). Este análisis demuestra que existen diferencias en las frecuencias alélicas de genes relacionados con la pigmentación entre poblaciones europeas. Estas diferencias son las que determinan que poblaciones norte-europeas tengan un color de piel, ojos y pelo más claro, y mayor número de efélides, que las poblaciones del sur de Europa. En concordancia con nuestros resultados, estudios recientes han detectado cambios en la frecuencia alélica de variantes localizadas en genes de pigmentación (SLC45A2, SLC24A5 y HERC2) en el proceso de evolución de las diferentes poblaciones de la especie humana, poniendo de manifiesto que la pigmentación cutánea basal y la respuesta al sol por bronceamiento son rasgos hereditarios que responden a una selección natural vía adaptación genética a la radiación solar (Mathieson y cols., 2015). Así pues, los africanos ancestrales tienen fijados alelos asociados a pigmentación oscura y, mediante un proceso de adaptación genética, la frecuencia de dichos alelos disminuye progresivamente en gradiente sur-norte con el objetivo de aclarar el color de la piel en zonas geográficas donde los niveles de radiación solar son menores. Un ejemplo claro es el gen SLC45A2, ya que la frecuencia del alelo ancestral de rs16891982 (asociado a pigmentación oscura) en la población española es mayor que en el resto de poblaciones europeas, seguramente debido a un proceso de selección a la mayor exposición solar que existe en España (Ibarrola-Villava y cols., 2011). Estas diferencias genotípicas explicarían el hecho de que la pigmentación cutánea basal en individuos de poblaciones Mediterráneas sea más oscura (Martinez-Cadenas y cols., 2013).

\section{Asociación de variantes genéticas con rasgos fenotípicos de sensibilidad solar}

Nuestros resultados confirman estudios previos que definen las variantes $\mathrm{RHC}$ del gen $M C 1 R$ como el mayor determinante del fenotipo pigmentario de riesgo característico de tener la piel clara que tras la exposición solar siempre se quema y nunca se broncea (fototipo cutáneo I/II), así como tener efélides (Jacobs y cols., 2015; Praetorius y cols., 2014; Scherer y Kumar, 2010). 
Por otro lado, nuestros resultados muestran una relación entre el polimorfismo rs12203592 localizado en el gen que codifica para el factor regulador de interferón 4 (IRF4) y la aparición de lesiones hiperpigmentarias benignas como efélides y lentigos solares. Por ejemplo, ser portador del alelo derivado $(T)$ de este polimorfismo incrementa casi el doble el riesgo relativo de tener efélides respecto a ser portador del alelo ancestral $(G)$. Este resultado parece concordante con estudios previos dónde determinadas variantes genéticas de IRF4 han sido asociadas a ciertos rasgos relacionados con la pigmentación cutánea basal, la sensibilidad cutánea a la exposición solar, la aparición prematura de canas, la aparición de pecas, y también con el riesgo a melanoma (Jacobs y cols., 2015; Peña-Chilet y cols., 2013; Praetorius y cols., 2013, 2014). Además de expresarse en células del sistema inmunitario y mediar en la respuesta inmunológica frente a infecciones víricas, este gen también se expresa en los melanocitos de la epidermis. La expresión de IRF4 tiene un efecto inductor en la síntesis de melanina, al incrementar los niveles de la tirosinasa (encima clave en la melanogéneis) en el interior del melanocito (Praetorius y cols., 2013). Asimismo, IRF4 coopera con MITF en la regulación de la expresión de $M C 1 R$ en el melanocito - gen clave en la activación de la vía de la pigmentación (Praetorius y cols., 2013).

Otro de los genes relacionados previamente con la pigmentación que ha sido incluido en el estudio esSLC45A2 - gen que codifica un transportador de solutos localizado en el melanosoma involucrado en la maduración del mismo (Ibarrola-Villava y cols., 2011; Scherer y Kumar, 2010). Son varios los estudios que han descrito variantes genéticas en este gen relacionadas con cambios en la pigmentación cutánea basal, así como con el riego a melanoma. Tal y como se explica anteriormente, el alelo ancestral del polimorfismo rs16891982 se asocia con color de piel, pelo y ojos oscuros, capacidad de responder a la exposición solar por bronceamiento y un menor riesgo de cáncer cutáneo (Ibarrola-Villava y cols., 2011; Scherer y Kumar, 2010). Los resultados obtenidos en nuestra población respaldan dichas observaciones previas, ya que la mayoría de individuos que presentan una mejor tolerancia a la exposición solar (fototipo cutáneo III/IV) son portadores del alelo ancestral C.

El gen que codifica para la proteína de señalización agouti $(A S P)$, ligando de $M C 1 R$ que antagoniza la función del receptor transmembrana, también ha sido intensamente estudiado debido a su importancia en el ratio eumelanina/feomelanina sintetizado en el interior del melanocito (Liu, Wen, y Kayser, 2013; Scherer y Kumar, 2010). En nuestra población española, rs4911442 parece estar implicada en la aparición de efélides vía alteración de los niveles de expresión del gen. Concretamente, el alelo $\mathrm{G}$ de esta variante genética incrementa la posibilidad de presentar efélides, seguramente debido a que este alelo activa la expresión de $A S P$ incrementando los niveles de agouti que, tras su unión con MC1R, inhibe la vía de la pigmentación favoreciendo la síntesis de feomelanina en detrimento de la síntesis de eumelanina (Jacobs y cols., 2015; Praetorius y cols., 2014).

Tener un elevado número de nevus no parece estar determinado por ninguna de las variantes genéticas incluidas en este estudio. Los nevus adquiridos son tumores benignos que surgen como consecuencia directa del daño causado por la radiación ultravioleta, favoreciendo la transformación de los melanocitos de la epidermis. Así pues, la presencia de mayor número de nevus vendría determinada por mutaciones somáticas adquiridas y no tanto por las mutaciones en línea germinal analizadas en este estudio (Baron y cols., 2014; Hernando, Ibarrola-Villava, Fernandez, y cols., 2016).

En conclusión, este estudio revela variantes genéticas que determinan rasgos de sensibilidad solar en individuos de origen español. Debido a que la pigmentación depende de la interacción entre varios genes, es interesante conocer si existe un efecto acumulativo en individuos portadores de varios polimorfismos asociados a fenotipo de riesgo, es decir, a tener una mayor susceptibilidad a la radiación solar y, por tanto, a padecer cáncer cutáneo. La 
identificación de variantes asociadas con rasgos fenotípicos que predisponen a cáncer de piel ofrece la oportunidad de estudiar su asociación con el riesgo de cáncer cutáneo, ya que la forma esporádica de cáncer de piel se desarrolla a través de la interacción con el medio ambiente y con factores de predisposición genética.

\section{Referencias bibliográficas}

Avilés, J. A., Lázaro, P., Fernández, L. P., Benítez, J., Ibarrola-Villava, M., y Ribas, G. (2012). Características fenotípicas e histológicas de los pacientes con melanoma cutáneo en función de los polimorfismos del MC1R. Actas Dermo-Sifiliograficas, 103(1), 44-50. https:// doi.org/10.1016/j.ad.2011.04.009

Baron, A. E., Asdigian, N. L., Gonzalez, V., Aalborg, J., Terzian, T., Stiegmann, R. A., Box, N. F. (2014). Interactions between ultraviolet light and MC1R and OCA2 variants are determinants of childhood nevus and freckle phenotypes. Cancer Epidemiol Biomarkers Prev, 23(12), 2829-2839. https://doi.org/10.1158/1055-9965.EPI-14-0633

Bastiaens, M., Huurne, J., Gruis, N., Bergman, W., Westendorp, R., Vermeer, B. J., y Bavinck, J. (2001). The melanocortin-1-receptor gene is the major freckle gene. Hum Mol Genet, 10(16), 1701-1708. https://doi.org/10.1093/hmg/10.16.1701

Candille, S. I., Absher, D. M., Beleza, S., Bauchet, M., McEvoy, B., Garrison, N. A., Shriver, M. D. (2012). Genome-Wide Association Studies of Quantitatively Measured Skin, Hair, and Eye Pigmentation in Four European Populations. PLoS ONE, 7(10), e48294. https://doi. org/10.1371/journal.pone.0048294

Córdoba-Lanús, E., Hernández-Jiménez, J. G., Medina-Coello, C., Espinoza-Jiménez, A., González, A., Rodríguez-Pérez, M. D. C., Fernández-De-Misa, R. (2014). MC1R gene variants and sporadic malignant melanoma susceptibility in the Canary Islands population. Archives of Dermatological Research, 306(1), 51-58. https://doi.org/10.1007/s00403-013-1420-z

Eriksson, N., Macpherson, J. M., Tung, J. Y., Hon, L. S., Naughton, B., Saxonov, S., Mountain, J. (2010). Web-based, participant-driven studies yield novel genetic associations for common traits. PLoS Genetics, 6(6), e1000993. https://doi.org/10.1371/journal.pgen.1000993

Ezzedine, K., Mauger, E., Latreille, J., Jdid, R., Malvy, D., Gruber, F., Guinot, C. (2013). Freckles and solar lentigines have different risk factors in Caucasian women. Journal of the European Academy of Dermatology and Venereology, 27(3), 345-56. https://doi. org/10.1111/j.1468-3083.2012.04685.x

Fernandez, L. P., Milne, R. L., Bravo, J., Lopez, J. M., Avilés, J. A., Longo, M. I., Ribas, G. (2007). MC1R: Three novel variants identified in a malignant melanoma association study in the Spanish population. Carcinogenesis, 28(8), 1659-1664. https://doi.org/10.1093/carcin/ bgm084

Hernando, B., Ibarrola-Villava, M., Fernandez, L. P., Peña-Chilet, M., Llorca-Cardeñosa, M., Oltra, S. S., Ribas, G. (2016). Sex-specific genetic effects associated with pigmentation, sensitivity to sunlight, and melanoma in a population of Spanish origin. Biology of Sex Differences, 7(17), 1-9. https://doi.org/10.1186/s13293-016-0070-1

Hernando, B., Ibarrola-Villava, M., Peña-Chilet, M., Alonso, S., Ribas, G., y Martinez-Cadenas, C. (2016). Sex and MC1R variants in human pigmentation: Differences in tanning ability and sensitivity to sunlight between sexes. Journal of Dermatological Science, 84(3), 346348. https://doi.org/10.1016/j.jdermsci.2016.09.004

Ibarrola-Villava, M., Fernandez, L. P., Alonso, S., Boyano, M. D., Peña-Chilet, M., Pita, G., Ribas, G. (2011). A customized pigmentation SNP array identifies a novel SNP associated with 
melanoma predisposition in the SLC45A2 gene. PLoS ONE, 64(4), e19271. https://doi. org/10.1371/journal.pone.0019271

Ibarrola-Villava, M., Pe, M., Llorca-Carde, M. J., Oltra, S., Cadenas, C.-M., Bravo, J., y Ribas, G. (2014). Modeling MC1R Rare Variants: A Structural Evaluation of Variants Detected in a Mediterranean Case-Control Study. Journal of Investigative Dermatology, 134(4), 11461149. https://doi.org/10.1038/jid.2013.469

Jacobs, L. C., Hamer, M. A., Gunn, D. A., Deelen, J., Lall, J. S., Van Heemst, D., Nijsten, T. (2015). A Genome-Wide Association Study Identifies the Skin Color Genes IRF4, MC1R, ASIP, and BNC2 Influencing Facial Pigmented Spots. Journal of Investigative Dermatology, 135(7), 1735-1742. https://doi.org/10.1038/jid.2015.62

Law, M. H., MacGregor, S., y Hayward, N. K. (2012). Melanoma Genetics: Recent Findings Take Us Beyond Well-Traveled Pathways. Journal of Investigative Dermatology, 132(7), 17631774. https://doi.org/10.1038/jid.2012.75

Liu, F., Wen, B., y Kayser, M. (2013). Colorful DNA polymorphisms in humans. Seminars in Cell and Developmental Biology, 24(6-7), 562-575. https://doi.org/10.1016/j. semcdb.2013.03.013

Martinez-Cadenas, C., Penãa-Chilet, M., Ibarrola-Villava, M., y Ribas, G. (2013). Gender is a major factor explaining discrepancies in eye colour prediction based on HERC2/OCA2 genotype and the IrisPlex model. Forensic Science International: Genetics, 7(4), 453-460. https://doi.org/10.1016/j.fsigen.2013.03.007

Mathieson, I., Lazaridis, I., Rohland, N., Mallick, S., Patterson, N., Roodenberg, S. A., Reich, D. (2015). Genome-wide patterns of selection in 230 ancient Eurasians. Nature, 528(7583), 499-503. https://doi.org/10.1038/nature16152

Matichard, E., Verpillat, P., Meziani, R., Gérard, B., Descamps, V., Legroux, E., Soufir, N. (2004). Melanocortin 1 receptor (MC1R) gene variants may increase the risk of melanoma in France independently of clinical risk factors and UV exposure. J Med Genet, 41(2), e13. https:// doi.org/10.1136/jmg.2003.011536

Peña-Chilet, M., Blanquer-Maceiras, M., Ibarrola-Villava, M., Martinez-Cadenas, C., MartinGonzalez, M., Gomez-Fernandez, C., Ribas, G. (2013). Genetic variants in PARP1 (rs3219090) and IRF4 (rs12203592) genes associated with melanoma susceptibility in a Spanish population. BMC Cancer, 13(1), 160. https://doi.org/10.1186/1471-2407-13-160

Praetorius, C., Grill, C., Stacey, S. N., Metcalf, A. M., Gorkin, D. U., Robinson, K. C., Steingrimsson, E. (2013). A polymorphism in IRF4 affects human pigmentation through a tyrosinasedependent MITF/TFAP2A pathway. Cell, 155(5), 1022-1033. https://doi.org/10.1016/j. cell.2013.10.022

Praetorius, C., Sturm, R. A., y Steingrimsson, E. (2014). Sun-induced freckling: Ephelides and solar lentigines. Pigment Cell and Melanoma Research, 27(3), 339-350. https://doi. org/10.1111/pcmr.12232

Ryung Roh, M., Eliades, P., Gupta, S., Grant-Kels, J. M., y Tsao, H. (2015). Cutaneous melanoma in women. Int $J$ Womens Dermatol, 1(1), 21-25. https://doi.org/10.1016/j. ijwd.2015.01.001

Scherer, D., y Kumar, R. (2010). Genetics of pigmentation in skin cancer - A review. Mutation Research - Reviews in Mutation Research, 705(2), 141-153. https://doi.org/10.1016/j. mrrev.2010.06.002

Sulem, P., Gudbjartsson, D. F., Stacey, S. N., Helgason, A., Rafnar, T., Magnusson, K. P., Stefansson, K. (2007). Genetic determinants of hair, eye and skin pigmentation in Europeans. Nature Genetics, 39(12), 1443-52. https://doi.org/10.1038/ng.2007.13 